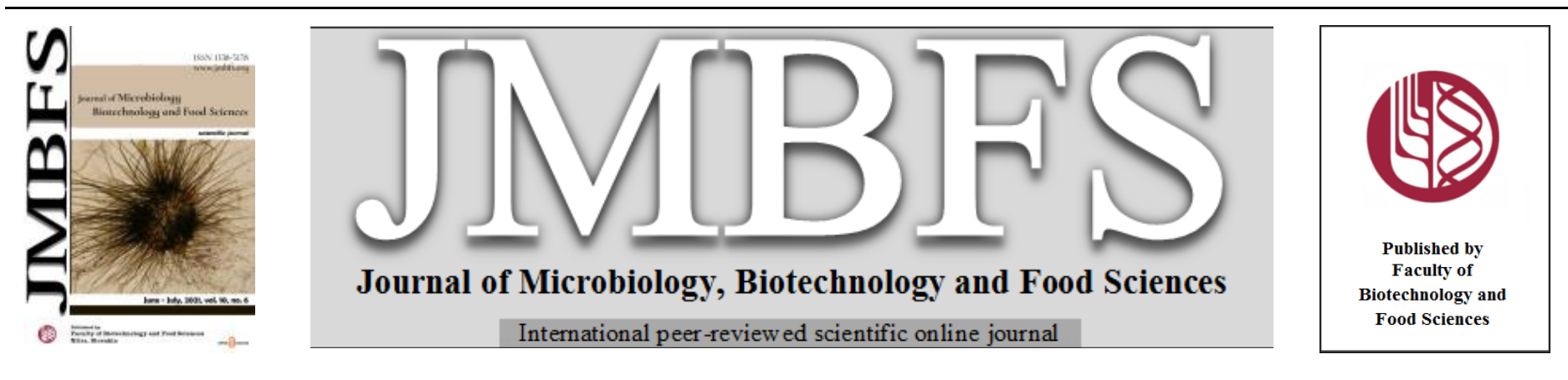

\title{
PRELIMINARY PROBIOTIC POTENTIAL OF SELECTED AEROCOCCUS SPP., ENTEROCOCCUS SPP., AND WEISELLA SP. FROM ALGERIAN GUEDID
}

\author{
Naimi Mostefa $*^{1-2}$, Abid Amar ${ }^{1}$ and Khaled Méghit Boumédiène $e^{2}$ \\ Address(es): \\ ${ }^{1}$ Applied Microbiology Laboratory,Bachir Nour University Center, Faculty of Science, Department of Biology, PO Box 900, El-Bayadh(32000), Algeria. \\ ${ }^{2}$ Research team nutrition and metabolic diseases (NUMED),Djillali Liabes University, Faculty of Natural Science and Life, Department of Biology, PO Box 89, Sidi- \\ bel-Abbes (22000), Algeria.
}

*Corresponding author: mostecoc@yahoo.fr

https://doi.org/10.15414/jmbfs.2937

\section{ARTICLE INFO}

Received 11. 4. 2020

Revised 7. 1. 2021

Accepted 20. 1.2021

Published 1. 6. 2021

Regular article open $\partial_{\text {ACCESS }}$

\begin{abstract}
Objective: The aim of the current study was to carry out probiotic criteria of ten candidates; 5 Aerococcus spp., 4 Enterococcus spp., and 1 Weisella sp. from Algerian culinary Guedid prepared traditionally to preserve and improve sensory and nutritional quality of this product.

Methods: Antimicrobial activity, acidity, growth Kinetics, quantification, heat and enzymes sensitivities were assayed against Listeria ivanovii CECT148, Bacillus cereus ATCC11778, Staphylococcus aureus ATCC25923 and Clostridium perfringens CECT486. Assessment of proteolysis, lipolysis, amylolysis, gelatinase, bile salts hydrolase, acetoin and exopolysaccharides production, acidity conditions, bile salts, gastric and intestinal resistances were determined. Survival lactic acid bacteria was then calculated using single plate-serial dilution spotting. Cholesterol assimilation, hemolysis and antibiotic resistance were also characterized. Statistical analysis was performed using originPro v9.5.

Results: The neutralized supernatants of Aerococcus spp. (Lbm19, 18, 3) and Enterococcus sp. (Lbm49, 46, 50) showed $9 \mathrm{~mm}$ inhibition zone, Clostridium. perfringens CECT486 was the most sensitive one. Lactic acid bacteria decreased by $1-2 \log \mathrm{CFU} / \mathrm{mL}$ on gastrointestinal conditions and assimilated cholesterol by up to $89 \%$. The antagonistic peak was obtained at the stationary phase where $\mathrm{pH} 3.5$ was reached. The supernatant was sensitive to enzymes and heat. All candidates showed digesting ability for proteins but not for starch, lipids, gelatin, bile salts, also showed no hemolytic activity. All candidates were found to resist against two antibiotics and three isolates exhibited negative for exopolysaccharides and acetoin production.

Conclusion: Enterococcus sp.Lbm49, Aerococcus sp.Lbm19, Aerococcus sp.Lbm18, Enterococcus sp.Lbm46, and Aerococcus $s p$.Lbm3 showed the highest potential probiotic score. This study should be completed by a molecular characterization, ex vivo and in vivo tests.
\end{abstract}

Keywords: Guedid, lactic acid bacteria, screening, probiotic potential

\section{INTRODUCTION}

Lactic acid bacteria (LAB) are ubiquitous, unicellular gram positive, nonsporulating, catalase-negative, facultative anaerobic microorganisms. LAB are frequently found in food and traditional ones. As well, they live in a bacterial ecosystem such as the vagina and gastrointestinal tract (Quinto et al., 2014). They are heterotrophic that generate energy from carbon substrates fermentation to produce organic acids such as lactic acid as one of the main fermentation products (Quinto et al., 2014; Carr $\boldsymbol{e t}$ al., 2002). LAB are generally recognized as safe "GRAS" by the agency of the Food and Drug Administration (FDA) or qualified presumption of safety "QPS" by the European agency of the Food Safety Authority (EFSA). These friendly human microbes are essentially utilized as food, food supplements, food ingredients, medical food, recently, as drugs, for therapeutic purposes to enhance human health and treatment of some gastrointestinal microbial disorders. This is due to their ability to inhibit harmful bacteria (Mokoena, 2017; Urdaci et al., 2004). This inhibition is related to the production of organic acids and various other metabolites; bacteriocins mainly (Izuchukwu, 2017; Hor and Liong, 2014; Lairini et al., 2014; Guarner et al.,2011).

The International Scientific Association for Probiotics and Prebiotics (ISAPP) defined probiotics as "a live organism, which provides a benefit to the host when provided in adequate quantities" (de Oliveira, 2018; Gasbarrini et al., 2016). Health benefits of probiotics include beneficial effects in prevention of diarrhea, inflammatory bowel disease, urogenital infections, lactose intolerance, lowering serum cholesterol level, colon cancer, regulation of microbial balance of intestinal microbiota, prevention of allergies, enhancement of the immune system, nutrient bioavailability, and calcium absorption (Angmo et al., 2016 ; Tokatll et al., 2015).
To ensure that the probiotic candidate strains exert their beneficial effect on human health, several required characteristics main currently examined, through in vitro tests as recommended by FAO/WHO guidelines (Morelli and Capurso, 2012; FAO/WHO, 2002). Taxonomic identification must be achieved using reliable phenotypic and molecular techniques (Reid, 2005). The origin of the strain must be human origin, preferably from the same site to obtain maximum efficiency and effectiveness. Those probiotic strains must be assessed by clinical trials on animals and on humans to avoid side effect. In addition, they must display an antimicrobial activity and resist to the gastrointestinal environment (Zhang et al., 2018; Ashraf and Smith, 2016). A high percentage to adhere to the intestinal cell epithelium or mucosa is an essential property. It may eventually stimulate the immune system through mucin production and prevent the implantation of pathogens. Antibiotic susceptibility profile is the most important parameter for the LAB candidates, to exclude transferability of antibiotic resistance to commensal or pathogen bacteria present inside the gut (Zhang $\boldsymbol{e t}$ al., 2018; Sanders, 2011; Foligne et al., 2013).

We carried out this study aiming to screen, through a series of tests, functional, technological, and safety proprieties of ten (10) autochthonous LAB. Those LAB were previously isolated from an ethnic Algerian salted and dried meat (Guedid), characterized at the genus level by phenotypic tests and selected for possessing an important antibacterial activity.

\section{MATERIAL AND METHODS}

\section{Laboratory bacterial strains and culture media}

The four gram-positive potentially pathogenic bacteria used in the current study as target strains were: Listeria ivanovii CECT148, Bacillus cereus ATCC11778, Staphylococcus aureus ATCC25923, and Clostridium perfringens CECT486. 
Working target strains were activated in TSB broth and/or agar (Trypticase Soy broth; Condalab) for 24 hours at $37^{\circ} \mathrm{C}$. The ten autochthonous LAB used in the current study as test cultures: Aerococcus spp. (Lbm3, 10, 17, 18 and 19), Enterococcus spp. (Lbm46, 47, 49 and 50) and Weisella sp. Lbm22, were obtained from Guedid prepared from lamb meat by salting and sun-drying (Gagaoua, and Boudechicha, 2018; Boudechicha et al., 2017). Samples from homemade preparation were collected in sterile bags. LAB were isolated on elective growth MRS agar (De Man, Rogosa, \&Sharpe; Condalab) and phenotypically identified (Axelsson 2004; Doyle et al., 2006). Working LAB cultures were activated in MRS broth and/or agar for 24 to 72 hours at $30^{\circ} \mathrm{C}$ under anaerobic atmosphere. Pathogens and LAB were regularly checked out by catalase reaction test and gram staining with microscopic observation according to standard procedures (Goldman and Green, 2015). Their stock cultures were maintained in their respective media; as refrigerate stock in agar slants at $4^{\circ} \mathrm{C}$ and as frozen stock in $20 \%(\mathrm{v} / \mathrm{v})$ glycerol-supplemented broth at $-20^{\circ} \mathrm{C}$ (Spencer, 2001)

\section{Antagonistic activity against pathogenic bacteria}

Antibacterial activity was screened using two methods: agar spot test in dual culture and agar well diffusion assay. The first assay was employed for the direct detection of antibacterial activity as described by Fleming et al. (1975) and Schillinger and Lücke (1989). An overnight LAB cultures $\left(30^{\circ} \mathrm{C}\right.$ on MRS agar) were spotted on the surface of solidified MRS base agar (1.5\% agar) seeded with $200 \mu \mathrm{l}$ (approximately $10^{8} \mathrm{CFU} / \mathrm{mL}$ ) of the target pathogenic bacteria standardized at $0.5 \mathrm{McFarland}$ from overnight cultures $\left(37^{\circ} \mathrm{C}\right.$ in TSB broth). The plates were incubated under anaerobic atmosphere at $30^{\circ} \mathrm{C}$ for 24 hours. The second assay was used for the indirect detection to determine the cell-free supernatants (CFS) antibacterial activity as described by Schillinger and Lücke (1989). Culture supernatants $\left(6000 \mathrm{rpm}\right.$ for 15 minutes at $\left.4^{\circ} \mathrm{C}\right)$ from overnigh cultures (MRS broth inoculated with $0.2 \%$ of LAB fresh cultures and incubated at $30^{\circ} \mathrm{C}$ for 48 hours) were treated at $80^{\circ} \mathrm{C}$ to eliminate vegetative forms for 10 min and then refrigerated at $4^{\circ} \mathrm{C}$. Ten $(10) \mathrm{mL}$ of solidified TSA (Trypticase Soy agar; Condalab) base agar (1.5\% agar) were overlaid with $10 \mathrm{~mL}$ TSA soft agar $\left(0.75 \%\right.$ agar) inoculated with $200 \mu \mathrm{l}$ (approximately $10^{8} \mathrm{CFU} / \mathrm{mL}$ ) of the target pathogenic bacteria standardized at $0.5 \mathrm{McFarland}$ from overnight cultures $\left(37^{\circ} \mathrm{C}\right.$ in TSB broth). Wells (7 $\mathrm{mm}$ in diameter) were bored at equal distance on the solidified TSA agar and filled with $40 \mu \mathrm{l}$ of culture supernatants. The central well, as control, received $40 \mu \mathrm{l}$ of sterile MRS broth. The plates were stored at room temperature $\left(20^{\circ} \mathrm{C}\right.$ for 2 hours $)$ until the culture supernatant was absorbed $\mathrm{LAB}$ were tested in duplicate and incubated under anaerobic atmosphere at $30^{\circ} \mathrm{C}$ for 24 hours.

Anaerobic conditions were ensured to bypass catalase inhibition as reported by Vermeiren et al., 2004 and a buffered TSA agar, at pH 7.0 and 0.2 M, was utilized to avoid acid inhibition. The buffered TSA agar was prepared by dissolving 19.5 parts of $\mathrm{K}_{2} \mathrm{HPO}_{4}$ at $0.1 \mathrm{M}$ with 30.5 parts $\mathrm{KH}_{2} \mathrm{PO}_{4}$ at $0.1 \mathrm{M}$ in a total of 100 parts of distilled water. The presence of inhibition zone (inhibition halo), surrounding the test culture spot or the culture supernatant higher than 0.5 $\mathrm{mm}$, was considered as positive antagonistic activity (Fleming et al., 1975). Both assays were performed in duplicate.

\section{Acidity, growth kinetics and production of bacteriocin-like substances}

Determination of acidity, growth kinetics and production of bacteriocin-like substances were carried out during the same experiment. From overnight cultures of LAB, MRS broth was inoculated with $0.2 \%$ and incubated at $30^{\circ} \mathrm{C}$ with shaking (100 rpm/min), Samples were collected after 0, 2, 6, 12, 18, 24, and 48 hours. Acidity was measured by $\mathrm{pH}$-meter, optical density by spectrophotometer at $620 \mathrm{~nm}$, and bacteriocin-like substances production was investigated by agar well diffusion assay on buffered TSA agar as noted above. The experiment was performed in duplicate (Musikasang et al., 2012; Musikasang et al., 2009).

\section{Heat and enzymes sensitivities of bacteriocin-like substances}

Samples of CFS obtained by centrifugation ( $6000 \mathrm{rpm}$ for 15 minutes at $4^{\circ} \mathrm{C}$ ) from an overnight test cultures in MRS broth inoculated with $0.2 \%$ of fresh LAB incubated at $30^{\circ} \mathrm{C}$ for 48 hours. Samples were treated at $100^{\circ} \mathrm{C}$ for 10,30 , and 60 $\min$ and at $120^{\circ} \mathrm{C}$ for $15 \mathrm{~min}$, then were cooled at $4^{\circ} \mathrm{C}$. Other samples were exposed to the action of two proteolytic enzymes (pepsin and $\alpha$ chymotrypsin at a final concentration of $1 \mathrm{mg} / \mathrm{mL}$ ) (Sigma-Aldrich). Resistance or sensitivity of CFS containing bacteriocin-like substances after these treatments were determined by the fact of the presence or absence of antibacterial activity by agar well diffusion assay applied as noted above. All tests were performed in duplicate (Hanchi et al., 2014; Monteagudo-Mera et al., 2011).

\section{Exopolysaccharides and acetoin production}

Capacity to produce exopolysaccharides (EPS) was determined on modified MRS agar with $10 \%(\mathrm{w} / \mathrm{v})$ sucrose (Sigma-Aldrich). Overnight LAB cultures (MRS agar at $30^{\circ} \mathrm{C}$ for 24 hours) were streaked on the surface of the agar. After incubation at $30^{\circ} \mathrm{C}$ for 24 to 48 hours, was considered as positive result streaks with viscous colonies (Angmo et al., 2016). For the capacity to produce acetoin, $1 \mathrm{~mL}$ from the overnight LAB cultures (MRS broth at $30^{\circ} \mathrm{C}$ for 24 hours) was inoculated in Clark Lubs broth (Condalab). After incubation at $30^{\circ} \mathrm{C}$ for 24 hours, $0.5 \mathrm{~mL}$ of both VP1 and VP2 reagents were added. Ten (10) minutes of rest at room temperature, acetoin production is indicated by pink ring and/or the diffusion of the pink color on the surface of the tube. Each experiment was performed in triplicate.

\section{Assessment of proteolytic, lipolytic, amylolytic, and bile salts hydrolase}

Assessment of proteolytic, lipolytic, amylolytic, and bile salts hydrolase activities was performed on modified MRS agar containing skimmed milk $(1 \%, 2 \%$, and $10 \% \mathrm{w} / \mathrm{v})$, tween $80($ at $1 \%$ and $3 \% \mathrm{v} / \mathrm{v})$, soluble starch $(2 \% \mathrm{w} / \mathrm{v})$, and bile salts $\left(0.5 \%\right.$ w/v with $0.037 \%$ of $\mathrm{CaCl}_{2}$ w/v) (for all reagents Sigma-Aldrich), respectively. Overnight LAB cultures (MRS agar at $30^{\circ} \mathrm{C}$ for 24 hours) were spotted on the surface of media. After incubation at $30^{\circ} \mathrm{C}$ for 24 to 48 hours, a positive activity was indicated by higher than $1 \mathrm{~mm}$ clear zone around the spot The starch agar plate must be flooded with iodine solution and examined 15-30 min later. The zone diameters were then measured. Experiment was performed in duplicate (Ruiz Rodríguez et al., 2016; Musikasang et al., 2012; MonteagudoMera et al., 2011; Musikasang et al., 2009).

Surviving in acidity conditions, bile salts, simulated gastric, and intestina juice

The capacity of the LAB to survive in acidity conditions was tested in phosphatebuffering saline (PBS) adjusted to $\mathrm{pH} 2$ and $3\left(0.9 \% \mathrm{NaCl}, 0.9 \% \mathrm{~K}_{2} \mathrm{HPO}_{4}, 0.15 \%\right.$ $\mathrm{KH}_{2} \mathrm{PO}_{4}$ ). The capacity to survive in gastric and intestinal conditions was also tested in a saline solution $(0.85 \% \mathrm{NaCl})$ supplemented with $3 \mathrm{mg} / \mathrm{mL}$ of pepsin adjusted to $\mathrm{pH} 3$ and with $3 \mathrm{mg} / \mathrm{mL}$ of bile salts adjusted to $\mathrm{pH} 8$ (for all reagents Sigma-Aldrich), respectively. These broths were inoculated by aliquots from overnight $\mathrm{LAB}$ cultures (MRS broth at $30^{\circ} \mathrm{C}$ for 24 hours) to attend $10^{8} \mathrm{CFU} / \mathrm{mL}$. These preparations were examined before and after 4 hours of incubation at $37^{\circ} \mathrm{C}$ and survival $\mathrm{LAB}$ were then calculated using single plate-serial dilution spotting (SP-SDS) on MRS agar in duplicate. Percentages of survival LAB were calculated as follow: \% survival $=(\log$ CFU of viable cells survived / log CFU of initial viable cells inoculated) x 100 (Ruiz Rodríguez et al., 2016; SerranoNino et al., 2016; Tokatlı et al., 2015; Oh and Jung, 2015; Thomas et al., 2015).

\section{Cholesterol assimilation}

Cholesterol assimilation was assayed in MRS Broth supplemented with $50 \mu \mathrm{g} / \mathrm{mL}$ of cholesterol (Quimicaclinica) and inoculated with $1 \%$ of overnigh LAB cultures (MRS broth at $30^{\circ} \mathrm{C}$ for 24 hours) standardized at $10^{8} \mathrm{CFU} / \mathrm{mL}$. After incubation at $30^{\circ} \mathrm{C}$ for 24 hours, CFS $\left(6000 \mathrm{rpm}\right.$ for $15 \mathrm{~min}$ at $\left.4^{\circ} \mathrm{C}\right)$ and inoculated control (sterile MRS broth) were assayed for their cholesterol content by spectrophotometry at $505 \mathrm{~nm}$. The difference in cholesterol content between the control and the CFS was considered as a percentage of assimilated cholesterol (Dubey and Jeevaratnam, 2015; Tokatlı et al., 2015).

\section{Hemolysis, gelatinase and antibiotic resistance}

For safety considerations, hemolysis was searched on $\mathrm{MH}$ agar (Muller Hinton; Condalab) supplemented with $5 \%$ of human fresh blood. Overnight LAB cultures (MRS agar at $30^{\circ} \mathrm{C}$ for 24 hours) were streaked on the surface of the medium. After incubation at $30^{\circ} \mathrm{C}$ for 24 to 48 hours, hemolytic activity was confirmed by the presence of a clear zone around bacterial streak. Were considered as nonhemolytic (green zones; $\alpha$-hemolysis or non-staining; $\gamma$-hemolysis) and hemolytic (yellow zones; $\beta$-hemolysis) (Angmo et al., 2016; Leite et al., 2015; Oh and Jung, 2015; Rather et al., 2015; Monteagudo-Mera et al., 2011). Gelatinase was searched on modified MRS agar containing gelatin $(3 \% \mathrm{w} / \mathrm{v})$. Overnight LAB cultures (MRS agar at $30^{\circ} \mathrm{C}$ for 24 hours) were streaked on the surface of MRS gelatin agar. After incubation at $30^{\circ} \mathrm{C}$ for 24 to 48 hours, the surface of the medium was sprayed by a saturated solution of ammonium sulphate $\left(\mathrm{NH}_{4}\right) \quad 2 \mathrm{SO}_{4}$ (Sigma-Aldrich) to make detectable halos of lysis (Monteagudo-Mera et al. 2011). The experiment was performed in triplicate.

Antibiotic resistance of the ten LAB to 11 antibiotics from different classes: penicillin $\left(10 \mu \mathrm{g} \cdot \mathrm{disk}^{-1}\right)$, ampicillin $\left(10 \mu \mathrm{g} \cdot \mathrm{disk}^{-1}\right)$, amoxicillin $\left(30 \mu \mathrm{g} \cdot \mathrm{disk}^{-1}\right)$ ceftiofur $\left(30 \mu \mathrm{g} \cdot \mathrm{disk}^{-1}\right)$, oxytetracyclin $\left(30 \mu \mathrm{g} \cdot \mathrm{disk}^{-1}\right)$, tylosin $\left(10 \mu \mathrm{g} \cdot \mathrm{disk}^{-1}\right)$, sulfadiazin $\left(10 \mu \mathrm{g} \cdot \mathrm{disk}^{-1}\right)$, florfinicol $\left(10 \mu \mathrm{g} \cdot \mathrm{disk}^{-1}\right)$, vancomycin $\left(30 \mu \mathrm{g} \cdot \mathrm{disk}^{-1}\right)$, erythromycin $\left(15 \mu \mathrm{g} \cdot \mathrm{disk}^{-1}\right)$, and gentamicin $\left(1 \mu \mathrm{g} \cdot \mathrm{disk}^{-1}\right)$ (for all antibiotics Oxoid, Australia), was characterized using Kirby-Bauer disc diffusion test. MRS agar was inoculated by swabbing overnight LAB cultures (MRS broth at $30^{\circ} \mathrm{C}$ for 24 hours) standardized at $10^{8} \mathrm{CFU} / \mathrm{mL}$. Discs were placed onto the surfaces of MRS agar. After incubation at $30^{\circ} \mathrm{Cfor} 24$ hours, clear zones (zones of inhibition) around the discs including the disc diameter were measured and expressed in millimeters. Susceptibility was calculated as follow: number of resistances / number of antibiotics tested (Angmo et al., 2016; Ruiz Rodríguez 
et al., 2016; Dubey and Jeevaratnam, 2015; Oh and Jung, 2015; VeraPingitore et al., 2016; Musikasang et al., 2012; Kohajdová, 2006).

\section{Statistical analysis}

Statistical analysis was performed using originPro v9.5. Probiotic and technological potential was calculated as (observed score / maximum score) $\mathrm{x}$ 100. Indication of score was: (0) lytic / no producer or (1) no lytic / producer for technological properties, and (0) sensitivity or (1) resistance for functional properties.

\section{RESULTS AND DISCUSSION}

\section{Antimicrobial activity assessment}

Potential bacteria candidates require minimum criteria in order to display probiotic status and exert their beneficial effect on human health. Antimicrobial activity represents the essential criteria due to inhibition of growth and attachment of pathogens in the intestine (FAO/WHO, 2002). In this study, we pointed out that the ten tested $\mathrm{LAB}$ inhibit pathogenic bacteria as follow: in the spot MRS agar test with 2 to $3 \mathrm{~mm}$ of diameter, two Aerococcus spp. (Lbm18 and 19), Enterococcus sp. Lbm46 and Weisella sp. Lbm22 could eliminate L. ivanovii CECT148, B. cereus ATCC11778, St. aureus ATCC25923 and C. perfringens CECT486. Concerning Enterococcus spp. (Lbm47, 49 and 50), they eliminated B. cereus ATCC11778, St. aureus ATCC25923 and C. perfringens CECT486. Aerococcus sp. Lbm17, eliminated L. ivanovii CECT148 and C.perfringens CECT486. The last two isolates Aerococcus spp. (Lbm3 and 10) eliminated only C.perfringens CECT486, However, in the agar well diffusion assay, two Aerococcus spp. (Lbm3 and 18) and Enterococcus sp. Lbm50 eliminated all target pathogens with a diameter of $9 \mathrm{~mm}$ (well included). Weisella sp. Lbm22 and Enterococcus sp. Lbm49 eliminated B. cereus ATCC11778, St. aureus ATCC25923 and C. perfringens CECT486. Aerococcus $s p$. Lbm19 exhibited inhibition against $L$. ivanovii CECT148, St. aureus ATCC 25923, and C.perfringens CECT486. C. perfringens CECT486 was the most sensitive pathogenic bacteria followed by B. cereus ATCC11778 and St. aureus ATCC2592 (Figure 1). LAB cultures were found to inhibit the growth of gram-positive pathogenic bacteria with variable inhibitory extents, as thus, in the study of Dhewa et al. (2010)10 to $12 \mathrm{~mm}$ of Lactobacilli cultures inhibition were found for gram-positive pathogens as $E$. faecalis, St. aureus and B. cereus. In addition, Angmo et al. (2016) found inhibition zones of about $5 \mathrm{~mm}$ against $B$. cereus, S. aureus, and $S$. dysenteriae. The pic of bacteriocinogenic activity $(9 \mathrm{~mm})$ versus L. ivanovii CECT148, B. cereus ATCC11778, St. aureus ATCC 25923 and C.perfringens CECT486 was obtained at the stationary phase where $\mathrm{pH} 3.50$ was reached (16 to 18 hours of culture). Regarding acidity, $\mathrm{pH}$ ranging from 3.03 (Aerococcus $s p$. Lbm 19) to 3.95 (Enterococcus spp. Lbm49) was reached and demonstrated by all LAB isolates (Figure 1). This could underline that our LAB candidates are considered as appropriate acidifiers by an accumulation of acids, manly lactic during lactic fermentations. Our results agree with those obtained by Hanchi et al. (2014) and Benreguieg et al. (2013) who reported at $\mathrm{pH} 2-3$ a pic of antimicrobial activity at a stationary phase between 12 and 18 hours. The results are displayed on Figure 2. Furthermore, the CFS of Aerococcus spp. (Lbm3, 17) and Enterococcus spp. (Lbm47, 49) isolates were heat-sensitive. However, the CFS of the rest of LAB were heat-resistant $\left(100^{\circ} \mathrm{C}\right.$ for 10,30 , and $\left.60 \mathrm{~min}\right)$. Furthermore, only CFS of Aerococcus spp. (Lbm3, 17) and Enterococcus spp. (Lbm47, 49) isolates were sensitive to enzymes (pepsin and $\alpha$ chymotrypsin). This sensitivity can predict the proteinaceous character of inhibitor factor, bacteriocin-like substances (Musikasang et al., 2012). Bacteriocin resistance for $\alpha$-chymotrypsin was reported (Monteagudo-Mera et al., 2011) (a)

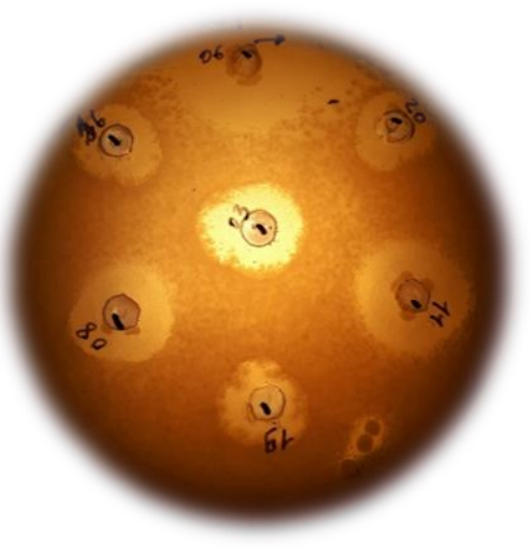

(b)

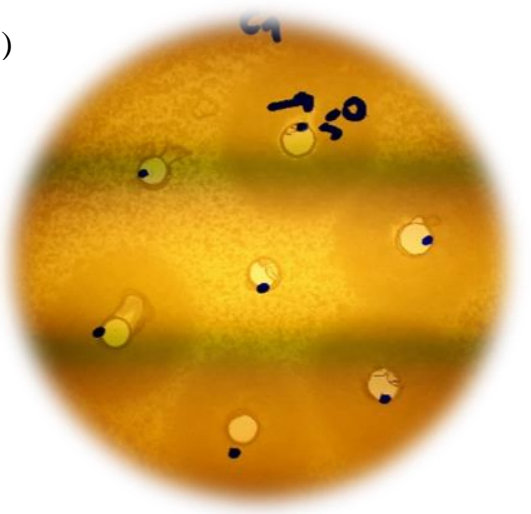

Figure 1 Antagonistic activity against St. aureus ATCC25923 of candidates LAB in the spot MRS agar (a) and in the agar well diffusion assay (b)
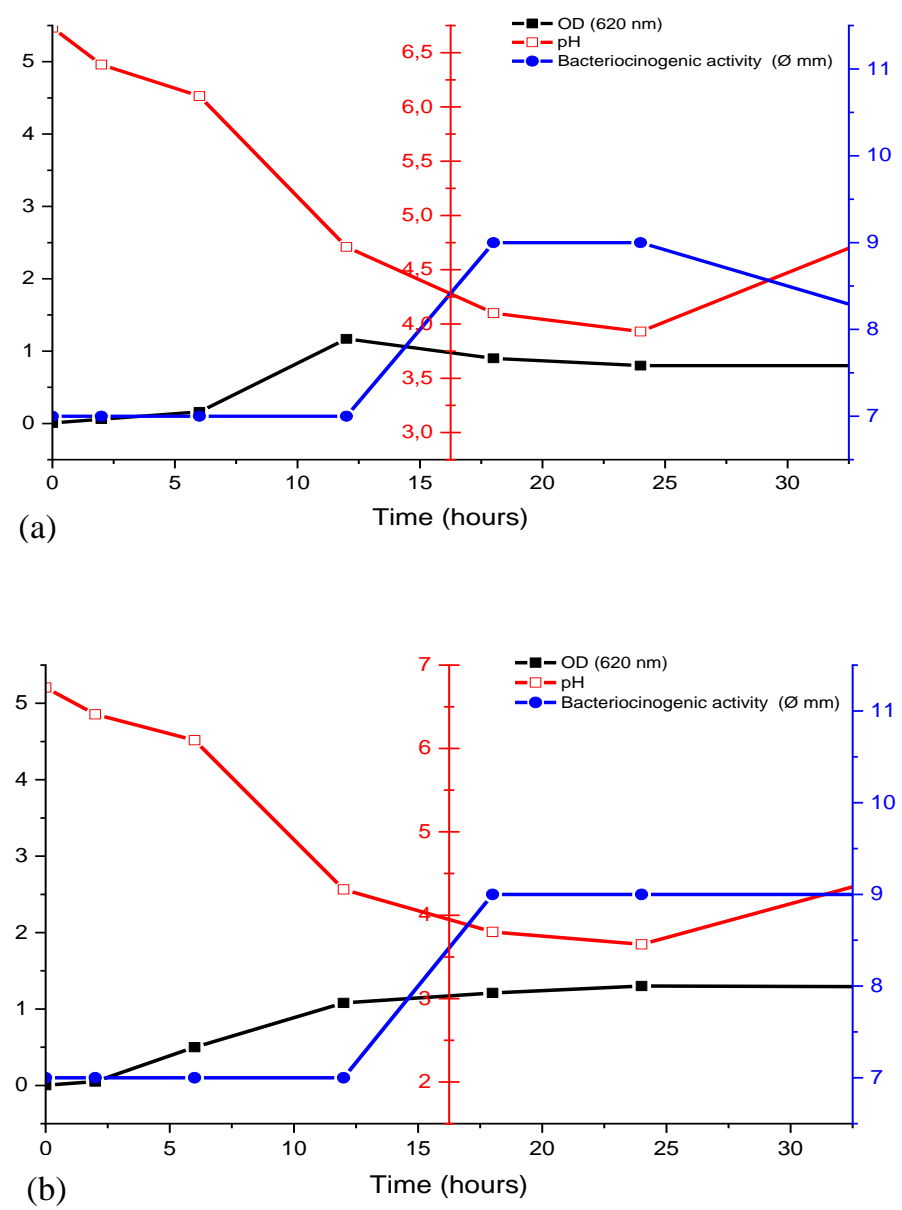


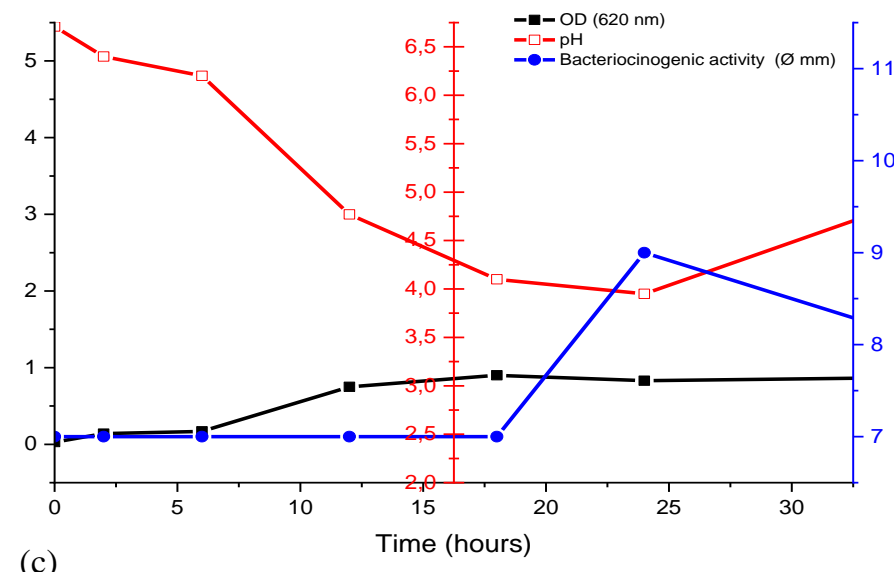

Figure 2 Acidity ( $\square$ ), growth kinetics, optical density (OD) at $620 \mathrm{~nm}(\mathbf{\square})$ and production of bacteriocin like substances anti-St. aureus ATCC 25923 (•) by (a) Enterococcus sp. Lbm46, (b) Enterococcus sp. Lbm49, and (c) Aerococcus spp. Lbm10.

\section{Technological properties assessment}

Approaches for improving probiotic status include but not limited to the selection of technological advantageous properties. All LAB tested exhibited protein digesting on modified MRS with skimmed milk at $2 \%$ and $10 \%$ with 17 to 22 $\mathrm{mm}$ for Aerococcus spp. (Lbm3, 10, 17, 18), Enterococcus sp. Lbm50 and Weisella sp. Lbm22, with 10 to $15 \mathrm{~mm}$ for Aerococcus sp. Lbm19 Enterococcus spp. (Lbm46, 47, 49). In comparison, Essid et al. (2009) found that L. plantarum have a proteolytic activity up to $5 \mathrm{~mm}$ on $10 \%$ skimmed milk. However, digesting capacity on modified MRS was not exhibited for protein at $1 \%$, starch at $3 \%$, and lipids at $1 \%$ and $3 \%$ of tween 80 . Numerous probiotic studies with various strains showed negative results for amylolytic and lipolytic activities (Mechai et al., 2014; Musikasang et al., 2012; Musikasang et al., 2012; Musikasang et al., 2009 ; Essid et al., 2009). In fact, meat substrate, muscle proteins and fat, should be more suitable to assess lipolytic and proteolytic activities than commonly used substrates such as powdered milk, gelatin, and Tween 80 (Essid et al., 2007; Mauriello et al., 2004). EPS production was demonstrated only by Aerococcus $s p$. Lbm10 and Enterococcus sp. Lbm50, while, acetoin production was demonstrated by Aerococcus spp. (Lbm3, 18) and Enterococcus spp. (Lbm46, 47, 49 and 50), excepting three isolates Aerococcus spp. (Lbm17, 19) and Weisella sp. Lbm22 which appeared neither EPS nor acetoin producers. Quinto et al. (2014) highlights the benefits of EPS in the resistance to acid.

\section{Functional properties assessment}

The selection criteria for potential probiotic candidates include also abilities to survive gut transit (Giraffa et al., 2010), as well as their abilities to resist gastric acidity and bile salts in the small intestine (Lähteinen et al., 2010). The $\mathrm{pH}$ of the stomach ranges from 2.5 to 3.5 and bile salts concentration reaches to $0.3 \%$, reason why they are considered as standard to assess gastric and intestina tolerance (Ashraf and Smith, 2016; Tokatlı et al., 2015; Leite et al., 2015; Dubey and Jeevaratnam, 2015). For the capacity to survive gut transit, the ten $\mathrm{LAB}$ were found to resist $\mathrm{pH} 2$ less than $\mathrm{pH} 3$ with percentages ranging from $82.83 \%$ to $92.56 \%$ for Aerococcus spp. and from $93.16 \%$ to $97.09 \%$ for Enterococcus spp. and with $76.58 \%$ for Weisella sp. Lbm22 (Table 1). The decrease in cell viability was approximately $1-2 \log \mathrm{CFU} / \mathrm{mL}$ (in the two $\mathrm{pH}$ values tested). In comparison, different probiotic LAB displayed survival ability at $\mathrm{pH} 2.5$ up to $85 \%$ (Tokatlı et al., 2015) and reductions in counts at least 2 logarithmic units compared with controls (Leite et al., 2015 ). For others, the maximum $4.8 \log \mathrm{CFU} / \mathrm{mL}$ decline in viability at $\mathrm{pH} 2$ (Angmo et al., 2016) and $3.3 \log$ at pH 3 (Dhewa et al., 2010)

Table 1 Acidity resistance and cholesterol assimilation

In PBS adjusted top H 2 In PBS adjusted top H 3

t0

\begin{tabular}{llll}
\hline Lbm03 & $8.42 \pm 0.39$ & $7.76 \pm 0.32$ & 92.17 \\
\hline Lbm10 & $9.03 \pm 0.32$ & $8.36 \pm 0.22$ & 92.56 \\
\hline Lbm17 & $9.16 \pm 0.23$ & $8.42 \pm 0.35$ & 91.85 \\
\hline Lbm18 & $8.76 \pm 0.21$ & $7.26 \pm 0.07$ & 82.83 \\
\hline Lbm19 & $8.42 \pm 0.35$ & $7.26 \pm 0.73$ & 86.22 \\
\hline Lbm46 & $8.48 \pm 0.21$ & $8.23 \pm 0.35$ & 97.09 \\
\hline Lbm47 & $8.73 \pm 0.12$ & $8.42 \pm 0.46$ & 96.37 \\
\hline Lbm49 & $8.56 \pm 0.19$ & $8.15 \pm 0.74$ & 95.21 \\
\hline Lbm50 & $8.81 \pm 0.35$ & $8.20 \pm 0.05$ & 93. \\
\hline Lbm22 & $8.85 \pm 0.19$ & $6.78 \pm 0.83$ & 76.58
\end{tabular}

$\% \quad$ t1

t1

$\%$

In MRS broth supplemented with $50 \mu \mathrm{g} / \mathrm{mL}$ of cholesterol

Aerococcus spp.

eisella sp.

$\begin{array}{lll}8.17 & 8.27 \pm 0.10 \quad 98.18\end{array}$

97.33

97.33

$8.53 \pm 0.40$

93.12

$8.00 \pm 0.02$

94.52

$8.42 \pm 0.30 \quad 99.27$

99.27

$8.65 \pm 0.27$

99.09

$8.40 \pm 0.24$

98.15

97.68

$7.85 \pm 0.37 \quad 88.63$
$\% *$

$97.91 \pm 1.67$

$91.66 \pm 0.70$

$93.74 \pm 1.30$

$95.83 \pm 2.21$

$91.66 \pm 0.87$

$89.57 \pm 0.98$

$93.74 \pm 1.13$

$95.83 \pm 1.55$

$89.57 \pm 1.43$

$93.74 \pm 1.10$

Legend: t0 : initial time, $\mathrm{t} 4$ : after $4 \mathrm{~h}$ of incubation, $\%$ :percentage of survival LAB (log CFU), \%* : percentage of assimilated cholesterol

Values represented as mean \pm standard deviation

Table 2 Capacity to survive gut transit

\begin{tabular}{|c|c|c|c|c|c|c|c|}
\hline & & in saline & $\begin{array}{l}\text { Gastric } \\
\text { ution suspend } \\
\text { epsin adjustec }\end{array}$ & $3 \mathrm{mg} / \mathrm{ml}$ & $\begin{array}{r}\text { in saline solt } \\
\text { of bil }\end{array}$ & $\begin{array}{c}\text { Intestinal } \\
\text { on suspendin } \\
\text { alts adjusted }\end{array}$ & $\begin{array}{l}3 \mathrm{mg} / \mathrm{m} \\
8\end{array}$ \\
\hline \multirow{6}{*}{ Aerococcus spp. } & & to & $\mathrm{t} 1$ & $\%$ & t0 & $\mathrm{t} 1$ & $\%$ \\
\hline & Lbm03 & $10.44 \pm 0.46$ & $10.32 \pm 0.50$ & 98.80 & $10.74 \pm 0.95$ & $10.66 \pm 0.54$ & 99.28 \\
\hline & Lbm10 & $10.55 \pm 0.54$ & $10.17 \pm 0.25$ & 96.35 & $10.70 \pm 0.52$ & $10.26 \pm 0.79$ & 95.93 \\
\hline & $\operatorname{Lbm} 17$ & $10.55 \pm 1.09$ & $10.22 \pm 0.51$ & 96.88 & $10.53 \pm 0.30$ & $10.45 \pm 0.39$ & 99.24 \\
\hline & $\operatorname{Lbm} 18$ & $10.34 \pm 1.07$ & $10.45 \pm 0.43$ & 101.01 & $11.27 \pm 0.37$ & $10.38 \pm 0.64$ & 92.15 \\
\hline & Lbm19 & $10.65 \pm 0.66$ & $10.64 \pm 0.60$ & 99.88 & $10.65 \pm 0.69$ & $10.59 \pm 0.43$ & 99.48 \\
\hline \multirow{4}{*}{ Enterococcus spp. } & Lbm46 & $10.52 \pm 0.39$ & $9.98 \pm 0.51$ & 94.86 & $10.64 \pm 0.32$ & $10.41 \pm 0.56$ & 97.84 \\
\hline & $\operatorname{Lbm} 47$ & $10.66 \pm 0.15$ & $10.16 \pm 0.40$ & 95.30 & $10.63 \pm 0.58$ & $10.41 \pm 0.03$ & 97.91 \\
\hline & Lbm49 & $10.69 \pm 1.27$ & $10.04 \pm 0.46$ & 93.91 & $11.18 \pm 0.58$ & $10.33 \pm 0.04$ & 92.43 \\
\hline & Lbm50 & $10.45 \pm 1.07$ & $10.13 \pm 0.05$ & 96.97 & $10.95 \pm 0.98$ & $10.44 \pm 0.04$ & 95.34 \\
\hline Weisella sp. & $\operatorname{Lbm} 22$ & $10.60 \pm 0.01$ & $10.42 \pm 0.65$ & 98.36 & $10.95 \pm 0.90$ & $10.26 \pm 0.04$ & 93.62 \\
\hline
\end{tabular}

Legend: $\mathrm{t} 0$ : initial time, $\mathrm{t} 4:$ after $4 \mathrm{~h}$ of incubation, $\%$ :percentage of survival LAB $(\log \mathrm{CFU})$

Values represented as mean \pm standard deviation

Furthermore, LAB tested were able to survive after passing through the gastric for 4 hours, by $96.35 \%$ to $99 \%$ for Aerococcus spp. and from $93.91 \%$ to $96.97 \%$ for Enterococcus spp. and with $98.36 \%$ for Weisella sp. Lbm22. As for intestinal environments, survival variability ranged from $92.15 \%$ to $99.48 \%$ for Aerococcus 
spp. and from $92.43 \%$ to $97.91 \%$ for Enterococcus spp. and was $93.62 \%$ for Weisella sp. Lbm22 (Table 2). They were most tolerant to gastrointestinal stress factors with similar behavior and decreased by approximately 1-2 $\log$ CFU/mL in cell viability. This finding is in accordance with previous studies, that found minor reduction illustrating the high resistance to gastrointestinal passing (Hanchi $\boldsymbol{e t}$ al., 2014) and those reporting a decrease of approximately $3 \mathrm{log}$ $\mathrm{CFU} / \mathrm{ml}$ in simulated gut juices. As it is recommended that $6 \log$ at $7 \mathrm{log}$ $\mathrm{CFU} / \mathrm{mL}\left(10^{6}\right.$ at $\left.10^{7} \mathrm{CFU}\right)$ constitutes a minimum number of each viable probiotic strain at the end of their shelf life for the exhibition of health benefit (Ashraf and Smith, 2016; Angmo et al., 2016; Quinto et al., 2014).

Additionally, the ten LAB demonstrated no bile salts hydrolase at $0.5 \%$. Previous studies reported negative and positive results using different concentrations, where negative ones are frequently observed in weak concentrations $(0.05,0.10$ and $0.30 \%$ ). Concerning cholesterol reduction, hypocholesterolemic is a desired character. Tested LAB reduced its level by 89-97\% (Table 1). Different rates of cholesterol assimilation levels were cited using different strains and initial concentrations of cholesterol (Dubey and Jeevaratnam, 2015; Tokatl et al. 2015).

\section{Safety assessment}

Moreover, safety criteria for potential probiotic candidates require determination of the antibiotic resistance profile, hemolytic and gelatinase activities. The hemolytic activity of LAB candidates showed $\alpha$-hemolytic for Aerococcus spp. (Lbm10, 17, 18, 19) and Enterococcus spp. (Lbm46, 47, 49) and $\gamma$-hemolytic for Aerococcus sp. Lbm3, Enterococcus sp. Lbm50 and Weisella sp. Lbm22. LAB producing $\alpha$ - or $\gamma$-hemolysis were considered non-hemolytic (Rather et al., 2015; Maragkoudakis et al., 2009). All LAB showed no gelatinase activity. In most cases, probiotic bacteria candidates demonstrated no presence of this virulence factors (Angmo et al., 2016; Leite $\boldsymbol{e t}$ al., 2015). Such no presence of this virulence factors indicates the safety in the use of such LAB as probiotic cultures (Monteagudo-Mera et al., 2011; FAO/WHO, 2002).

All LAB were found to resist to vancomycin and sulfadiazin, whereas Enterococcus spp. resisted to oxytetracyclin and ceftiofur, except Enterococcus $s p$. Lbm50 resisted to only ceftiofur. Inversely, they were all sensitive for ampicillin, amoxicillin, tylosin, florfinicol, erythromycin and gentamicin Consequently, resistance coefficient was ranging from 0.28 to 0.10 and sensitivity coefficient was ranging 0.72 to 0.90 . Resistance for tetracycline, erythromycin, chloramphenicol, streptomycin and vancomycin is clearly reviewed (Quinto et al., 2014). These results are consistent with many previous tests reporting a vancomycin resistance (Angmo et al., 2016; Leite et al., 2015; Dubey and Jeevaratnam, 2015), and were weakly antibiotic resistant to response at the requirement to avoid transfer genes inside the gut microbiota (Mathur \& Singh, 2005) and thus were safe to use as potential probiotics (VeraPingitore et al., 2016).

\section{Probiotic and technological potential}

Enterococcus sp.Lbm49, Aerococcus sp. Lbm19, Aerococcus sp. Lbm18, Enterococcus sp. Lbm46, Aerococcus sp. Lbm3 and Enterococcus sp. Lbm50 isolates showed the highest potential probiotic score (up to $55 \%$ ).

\section{CONCLUSION}

The objective of the current work was to study the potential probiotic of 5 Aerococcus spp., 4 Enterococcus spp., and 1 Weisella sp. isolated from an Algerian traditional dried and salted meat (Guedid). The obtained results showed that the ten assessed LAB cumulate probiotic potential scores between (0-1) especially, Enterococcus sp. Lbm49, Aerococcus sp. Lbm19, Aerococcus sp. Lbm18, Enterococcus sp. Lbm46, Aerococcus sp. Lbm3 and Enterococcus sp. Lbm50 that displayed the highest potential probiotic score (up to 55\%). In addition, Aerococcus sp. Lbm18, Enterococcus sp. Lbm46, and Enterococcus sp. Lbm49, revealed the best technological properties. Finally, those promising candidates should be better characterized throughout a molecular assessment; and to be tested thorough ex vivo and in vivo to confirming their human or veterinary utilization as probiotics.

\section{REFERENCES}

Angmo, K., Kumari, A., \& Bhalla, T. C. (2016). Probiotic characterization of lactic acid bacteria isolated from fermented foods and beverage of Ladakh. $L W T$ food Science and Technology, 66, 428-435 https://doi.org/10.1016/j.lwt.2015.10.057

Anukam, K. C., \& Reid, G. (2007). Probiotics: 100 years (1907-2007) after Elie Metchnikoff's observation. Communicating current research and educational topics and trends in applied microbiology, 1, 466-474.

Ashraf, R., \& Smith, S. C. (2016). Commercial lactic acid bacteria and probiotic strains-tolerance to bile, pepsin and antibiotics. International Food Research Journal, 23(2), 777 .
Axelsson, L. (2004). Lactic acid bacteria: classification and physiology. FOOD SCIENCE AND TECHNOLOGY-NEW YORK-MARCEL DEKKER-, 139, 1-66. https://doi.org/10.1201/9780824752033.ch1

Benreguieg, M., Dalache, F., \& Gacemi, B. (2013). Characterization of antibacterial activity and potential as probiotic of lactic acid bacteria isolated from goat's milk in Algeria. Journal of Life Sciences, 7(8), 802 https://doi.org/10.17265/1934-7391/2013.08.004

Boudechicha, H. R., Nasri, I., Bennaceur, Z., Sellama, M., Hafid, K., Boudjellal, A., \& Gagaoua, M. (2017). Microbiological changes during the preparation steps of Khliaa Ezir: a traditional cured meat product of Algeria https://doi.org/10.15761/IFNM.1000199

Carr, F. J., Chill, D., \& Maida, N. (2002). The lactic acid bacteria: a literature survey. Critical reviews in microbiology,28(4), 281-370. https://doi.org/10.1080/1040-840291046759

Cicenia, A., Scirocco, A., Carabotti, M., Pallotta, L., Marignani, M., \& Severi, C. (2014). Postbiotic activities of lactobacilli-derived factors. Journal of clinical gastroenterology, 48, S18-S22. ttps://doi.org/10.1097/MCG.0000000000000231

de Oliveira, G. L. (2018). Probiotic Applications in Autoimmune Diseases. Probiotics-Current Knowledge and Future Prospects, 69-89. https://doi.org/10.5772/intechopen.73064

Dhewa, T., Bajpai, V., Saxena, R. K., Pant, S., \& Mishra, V. (2010). Selection of lactobacillus strains as potential probiotics on basis of in vitro attributes. International Journal of Probiotics \& Prebiotics, 5(1), 45.

Dubey, A. K., \& Jeevaratnam, K. (2015). Probiotic screening of Lactobacilli isolates from Uttapam batter fermented supplementing with Piper betle L. leaves. Advances in Microbiology, 5(13),

https://doi.org/10.4236/aim.2015.513090

Doyle, M. P., \& Meng, J. I. A. N. G. H. O. N. G. (2006). Bacteria in food and beverage production. Prokaryotes. Springer, New York, 797-811. https://doi.org/10.1007/0-387-30741-9 23

Essid, I., Medini, M., \& Hassouna, M. (2009). Technological and safety properties of Lactobacillus plantarum strains isolated from a Tunisian traditional $\begin{array}{llll}\text { salted meat. } \quad \text { Meat } & \text { 203-208 }\end{array}$ https://doi.org/10.1016/j.meatsci.2008.07.020

Essid, I., Ismail, H. B., Ahmed, S. B. H., Ghedamsi, R., \& Hassouna, M. (2007) Characterization and technological properties of Staphylococcus xylosus strains isolated from a Tunisian traditional salted meat. Meat science, 77(2), 204-212 https://doi.org/10.1016/j.meatsci.2007.03.003

Fleming, H. P., Etchells, J. L., \& Costilow, R. N. (1975). Microbial inhibition by an isolate of Pediococcus from cucumber brines. Appl. Environ. Microbiol., 30(6), 1040-1042. https://doi.org/10.1128/AEM.30.6.1040-1042.1975 Foligne, B., Daniel, C., \& Pot, B. (2013). Probiotics from research to market: the possibilities, risks and challenges. Current opinion in microbiology, 16(3), 284 292. https://doi.org/10.1016/j.mib.2013.06.008

Food and Agriculture Organization of the United Nations / World Health Organization. (2002). FAO/WHO Guidelines for the Evaluation of Probiotics in Food. FAO/WHO, London Ontario, Canada: https://www.who.int/foodsafety/fs_management/en/probiotic guidelines.pdf. Gagaoua, M., \& Boudechicha, H. R. (2018). Ethnic meat products of the North African and Mediterranean countries: an overview. Journal of Ethnic Foods, 5(2), 83-98. https://doi.org/10.1016/j.jef.2018.02.004

Gasbarrini, G., Bonvicini, F., \& Gramenzi, A. (2016). Probiotics history. Journal of clinical gastroenterology, 50, S116-S119. https://doi.org/10.1097/MCG.0000000000000697

Giraffa, G., Chanishvili, N., \& Widyastuti, Y. (2010). Importance of lactobacilli in food and feed biotechnology. Research in microbiology, 161(6), 480-487 https://doi.org/10.1016/j.resmic.2010.03.001

Goldman, E., \& Green, L. H. (2015). Practical handbook of microbiology. CRC press. https://doi.org/10.1201/b17871

Guarner, F., Khan, A. G., Garisch, J., Eliakim, R., Gangl, A., Thomson, A., ... \& De Paula, J. A. (2011). Probiotiques et prébiotiques. World Gastroenterology Organisation Global Guidelines.

Hanchi, H., Hammami, R., Kourda, R., Hamida, J. B., \& Fliss, I. (2014). Bacteriocinogenic properties and in vitro probiotic potential of enterococci from Tunisian dairy products. Archives of microbiology, 196(5), 331-344. https://doi.org/10.1007/s00203-014-0978-y

Hor, Y. Y., \& Liong, M. T. (2014). Use of extracellular extracts of lactic acid bacteria and bifidobacteria for the inhibition of dermatological pathogen $\begin{array}{llll}\text { Staphylococcus } & \text { aureus. Dermatologica } & \text { Sinica, 32(3), } & \text { 141-147. }\end{array}$ https://doi.org/10.1016/j.dsi.2014.03.001

Izuchukwu, N. (2017). Comparative Application of Different Strategies of Bacteriocins Produced by Carnobacterium maltaromaticium MMF-32 for Inhibition of Listeria monocytogenes ATCC 19114 in Cold-Smoked Haddock. American Scientific Research Journal for Engineering, Technology, and Sciences (ASRJETS), 38(2), 311-340.

KOHAJDOVÁ, G. G. A. Š. Z. (2006). In vitro testing of selected probiotic characteristics of Lactobacillus plantarum and Bifidobacterium longum. Journa of Food and Nutrition Research, 45(2), 77-83.

Lähteinen, T., Malinen, E., Koort, J. M., Mertaniemi-Hannus, U., Hankimo, T. Karikoski, N., ... \& Palva, A. (2010). Probiotic properties of Lactobacillus 
isolates originating from porcine intestine and feces. Anaerobe, 16(3), 293-300. https://doi.org/10.1016/j.anaerobe.2009.08.002

Lairini, S., Beqqali, N., Bouslamti, R., Belkhou, R., \& Zerrouq, F. (2014) Isolement des bactéries lactiques à partir des produits laitiers traditionnels Marocains et formulation d'un lait fermenté proche du Kéfir. Afrique Science: Revue Internationale des Sciences et Technologie, 10(4), 267-277.

Leite, A. M., Miguel, M. A. L., Peixoto, R. S., Ruas-Madiedo, P., Paschoalin, V. M. F., Mayo, B., \& Delgado, S. (2015). Probiotic potential of selected lactic acid bacteria strains isolated from Brazilian kefir grains. Journal of dairy science, 98(6), 3622-3632. https://doi.org/10.3168/jds.2014-9265

Mauriello, G., Casaburi, A., Blaiotta, G., \& Villani, F. (2004). Isolation and technological properties of coagulase negative staphylococci from fermented sausages of Southern Italy. Meat Science, 67(1), 149-158 https://doi.org/10.1016/j.meatsci.2003.10.003

Maragkoudakis, P. A., Mountzouris, K. C., Psyrras, D., Cremonese, S., Fischer, J., Cantor, M. D., \& Tsakalidou, E. (2009). Functional properties of novel protective lactic acid bacteria and application in raw chicken meat against Listeria monocytogenes and Salmonella enteritidis. International Journal of Food Microbiology, 130(3),

219-226.

https://doi.org/10.1016/i.ijfoodmicro.2009.01.027

Mathur, S., \& Singh, R. (2005). Antibiotic resistance in food lactic acid bacteriaa review. International journal of food microbiology, 105(3), 281-295 https://doi.org/10.1016/j.ijfoodmicro.2005.03.008

Mechai, A., Debabza, M., \& Kirane, D. (2014). Screening of technological and probiotic properties of lactic acid bacteria isolated from Algerian traditional fermented milk products. International Food Research Journal, 21(6), 2451.

Mokoena, M. P. (2017). Lactic acid bacteria and their bacteriocins: Classification, biosynthesis and applications against uropathogens: A minireview. Molecules, 22(8), 1255. https://doi.org/10.3390/molecules22081255

Monteagudo-Mera, A., Caro, I., Rodríguez-Aparicio, L. B., Rúa, J., Ferrero, M. A., \& García-Armesto, M. R. (2011). Characterization of certain bacterial strains for potential use as starter or probiotic cultures in dairy products. Journal of food protection, 74(8), 1379-1386. ttps://doi.org/10.4315/0362-028X.JFP-10-392

Morelli, L., \& Capurso, L. (2012). FAO/WHO guidelines on probiotics: 10 years later. Journal of clinical gastroenterology, 46, $\quad$ S1-S2 https://doi.org/10.1097/MCG.0b013e318269fdd5

Musikasang, H., Sohsomboon, N., Tani, A., \& Maneerat, S. (2012). Bacteriocinproducing lactic acid bacteria as a probiotic potential from Thai indigenous chickens. Czech J Anim Sci, 57(3), 137-149. https://doi.org/10.1007/s11274-0090020-8

Musikasang, H., Tani, A., H-kittikun, A., \& Maneerat, S. (2009). Probiotic potential of lactic acid bacteria isolated from chicken gastrointestinal digestive tract. World Journal of Microbiology and Biotechnology, 25(8), 1337-1345. https://doi.org/10.1007/s11274-009-0020-8

Oh, Y. J., \& Jung, D. S. (2015). Evaluation of probiotic properties of Lactobacillus and Pediococcus strains isolated from Omegisool, a traditionally fermented millet alcoholic beverage in Korea. LWT-food Science and Technology, 63(1), 437-444. https://doi.org/10.1016/j.lwt.2015.03.005

Quinto, E. J., Jiménez, P., Caro, I., Tejero, J., Mateo, J., \& Girbés, T. (2014). Probiotic lactic acid bacteria: a review. Food and Nutrition Sciences, 5(18), 1765 https://doi.org/10.4236/fns.2014.518190

Rather, I. A., Choi, K. H., Bajpai, V. K., \& Park, Y. H. (2015). Antiviral mode of action of Lactobacillus plantarum YML009 on Influenza virus H1N1. Bangladesh Journal of Pharmacology, 10(2), 475-482. https://doi.org/10.3329/bjp.v10i2.23068

Reid, G. (2005). The importance of guidelines in the development and application of probiotics. Current pharmaceutical design,11(1), 11-16. https://doi.org/10.2174/1381612053382395

Ruiz Rodríguez, L., Vera Pingitore, E., Rollan, G., Cocconcelli, P. S., Fontana C., Saavedra, L., ... \& Hebert, E. M. (2016). Biodiversity and technologicalfunctional potential of lactic acid bacteria isolated from spontaneously fermented quinoa sourdoughs. Journal of applied microbiology, 120(5), 1289-1301. https://doi.org/10.1111/jam.13104

Samot, J., \& Badet, C. (2013). Antibacterial activity of probiotic candidates for oral health. Anaerobe, 19, 34-38. https://doi.org/10.1016/j.anaerobe.2012.11.007 Sanders, M. E. (2011). Impact of probiotics on colonizing microbiota of the gut. Journal of clinical Gastroenterology, 45, S115-S119. https://doi.org/10.1097/MCG.0b013e318227414a

Schillinger, U., \& Lücke, F. K. (1989). Antibacterial activity of Lactobacillus sake isolated from meat. Appl. Environ. Microbiol., 55(8), 1901-1906. https://doi.org/10.1128/AEM.55.8.1901-1906.1989

Serrano-Nino, J. C., Solis-Pacheco, J. R., \& Gutlerrez-Padilla, J. A. (2016). Isolation and identification of lactic acid bacteria from human milk with potential probiotic role. J Food Nutr Res, 4(3), 170-177. https://doi.org/10.12691/jfnr-4-3$\underline{7}$

Spencer, J. F. (2001). Food microbiology protocols (Vol. 14). Springer Science \& Business Media. https://doi.org/10.1385/1592590292

Thomas, P., Sekhar, A. C., Upreti, R., Mujawar, M. M., \& Pasha, S. S. (2015) Optimization of single plate-serial dilution spotting (SP-SDS) with sample anchoring as an assured method for bacterial and yeast cfu enumeration and single colony isolation from diverse samples. Biotechnology Reports, 8, 45-55. https://doi.org/10.1016/i.btre.2015.08.003

Tokatlı, M., Gülgör, G., Bağder Elmacı, S., Arslankoz İşleyen, N., \& Özçelik, F. (2015). In vitro properties of potential probiotic indigenous lactic acid bacteria originating from traditional pickles. BioMed research international, 2015. https://doi.org/10.1155/2015/315819

Urdaci, M. C., Bressollier, P., \& Pinchuk, I. (2004). Bacillus clausii probiotic strains: antimicrobial and immunomodulatory activities. Journal of clinica gastroenterology, 38 ,

https://doi.org/10.1097/01.mcg.0000128925.06662.69

S86-S90.

Vera-Pingitore, E., Jimenez, M. E., Dallagnol, A., Belfiore, C., Fontana, C., Fontana, P., ... \& Plumed-Ferrer, C. (2016). Screening and characterization of potential probiotic and starter bacteria for plant fermentations. LWT-Food Science and Technology, 71, 288-294. https://doi.org/10.1016/j.1wt.2016.03.046

Vermeiren, L., Devlieghere, F., \& Debevere, J. (2004). Evaluation of meat born lactic acid bacteria as protective cultures for the biopreservation of cooked meat products. International journal of food microbiology,96(2), 149-164. https://doi.org/10.1016/j.ijfoodmicro.2004.03.016

Zhang, D., Zhang, S., Guidesi, E., Zonenschain, D., Sagheddu, V., Lee, S., ... \& Elli, M. (2018). Isolation and Characterization of New Probiotic Strains From Chinese Babies. Journal of clinical gastroenterology, 52, S27-S34. https://doi.org/10.1097/MCG.0000000000001113 